\title{
The Integration of a Big Data Framework and a Mobile Application on the iOS Platform to Support Smart Tourism
}

\author{
Pannee Suanpang and Pitchaya Jamjuntr
}

\begin{abstract}
The aim of this paper is to design a prototype that integrates a big data framework with a mobile application on an iOS platform to support smart tourism; a case study in Lampang Province, Thailand. The research approach used Software Development Life Cycle (SDLC) methodologies to analyze, design, implement and test user satisfaction of the system. The results found that the design of the big data model used Apache Hadoop to co-ordinate with Apache Spark as the big data processing framework. The mobile application system was designed and developed on an iOS platform that works with user interaction and receives various information from the data base that stores information about tourism such as tourist attractions, accommodation, spa products, health, food, tourism routes, and emergency contacts. etc. The mobile application system was used and evaluated for effectiveness and satisfaction of $\mathbf{4 0 0}$ users with an in-depth interview of 10 users. The results found that the overall mobile application evaluation in six categories found the highest score was the benefit of the mobile application system $(\bar{x}=4.46$, S.D. $=0.67)$, second the mobile application system design $(\bar{x}=4.43$, S.D. $=0.66)$, third the mobile application content design $(\bar{x}=4.32$, S.D. $=0.65)$ and finally the mobile application system ease of use $(\bar{x}$ $=4.32$, S.D. $=0.68$ ), respectively. Moreover, the qualitative results found that users were satisfied with the design, functionality, content, and the system overall.
\end{abstract}

Index Terms-Big data, education, mobile application, tourism.

\section{INTRODUCTION}

With the advancement of technology and innovations in Information Communication Technology (ICT) especially technology of mobile applications have colossal impact on business, education, industry and the public and private sectors [1]. Since the advent of internet technology on smartphones becoming a signification mechanism in the tourism information process and transaction via a digital platform [2], [3]. The tourist or customer conducts online transactions that related through travel including searching for information and trip planning, reservations for accommodation and restaurants and providing feedback through online surveys [1], [3]. The travel information process and transaction on digital platforms led to generate multiple types of data which are continuously growing within

Manuscript received July 25, 2019; revised March 15, 2020. This work was supported in part by the Suan Dusit University providing research funded "The wellness tourism potential development at Lampang province to become hub of Lanna wellness tourism" in year 2018 to support this project.

Pannee Suanpang is with the Suan Dusit University, Bangkok, Thailand (e-mail: dtechpannee@yahoo.com).

Pitchaya Jamjuntr is with Siam Technology College, Bangkok, Thailand (e-mail: pitchayajam@yahoo.com). social media sites (such as Facebook, Twitter, Line, etc.) and from mobile application services that allow users to upload digital photos, videos and posts which can create big data [4].

In such a big data era, big data is defined as "a new generation of technologies and architectures, designed to economically extract value from very large volumes of a wide variety of data, by enabling the high velocity capture, discover and/or analysis" [5]. Big data is characterized by the $3 \mathrm{Vs}$ model including Volume (bigger than traditional data set), Velocity (rapid speed of process and available) and Variety (different formats of data) [3], [6], [7]. Big data analytics is involved with the activities of specification, capture, storage, access and analysis of dataset to make content supported decisions [3], [8]. Big data is considered to be a highly potential tool to transform tourism to become "smart tourism". A smart tourism destination is created by a smart experience from the travel experience mediated by technologies and enhance through personalization and real time monitoring [9], [10]. Big data in the context of smart tourism can generate customer-based knowledge to support decision marking and improve the performance of the tourism business.

Moreover, it helps hotels and accommodation to better understand the target customers, optimize their process and drive business performance using business insight [1], [11]. Also, big data has attracted attention increasingly in tourism business such as tourism destination planning, hospitality management [11], customer relationship management [12], and destination marketing [13]. Consequently, a large amount of data has been created on tourist needs and behavior about tourism destination [3] such as web search data stored in web server log files [4], tourism mobile applications are used for planning travel and social media usage for sharing information. Tourism mobile applications become important because they generate data and provide information in various formats, according to the technical features of the mobile device that is designed to support information to the user and being dedicate to daily and tourism business activity [14].

Thailand is a world class destination, UNWTO [15]-United Nations World Tourism Organization ranked Thailand $9^{\text {th }}$ in the world, having 32.6 million International tourists in 2017 with a revenue of 1.65 trillion Baht that raked number three in the world. Currently, Thailand has a policy to develop the country with innovation under the policy of Thailand 4.0 and use new technology in the public and private sectors and especially in the tourism industry [15], [16]. With the advance of Internet technology leading to users using mobile applications and social media to support 
their travel in Thailand. Thus, information from mobile applications is becoming a significant factor to influence decision making when booking accommodation, selecting an airline, sharing tourist comments, build their community and finally sending feedback to the tourism business [16]. This has become a very important issue that requires new technology and architecture of big data that is integrated to a mobile application to support tourism activities to be more effective and efficient.

However, big data analysis technology and architecture is a low cost, fast acquisition, processing with analysis technology from a variety of large data with extraction [17]. Google, Map Reduce and Apache Hadoop have been widely used in the field of big data processing [17]. The data processing engine, big data analysis of tourism business needed to improve the traditional general system to reduce costs and improve efficiency. The use of a specialized system architecture has become a trend [3], [17].

The aim of this paper is to develop a prototype that integrates between a big data framework and a mobile application on iOS platform to support a smart tourism case study in Lampang province in Thailand. This study applied the System Develop Life Cycle (SDLC) methodology for analysis, design, implement and tested user's satisfaction of the mobile application on iOS platform to support a smart tourism system.

\section{REVIEW LITERATURES}

In this section there is a review of the literature that is related to the work involving the concept of big data and mobile applications to support tourism.

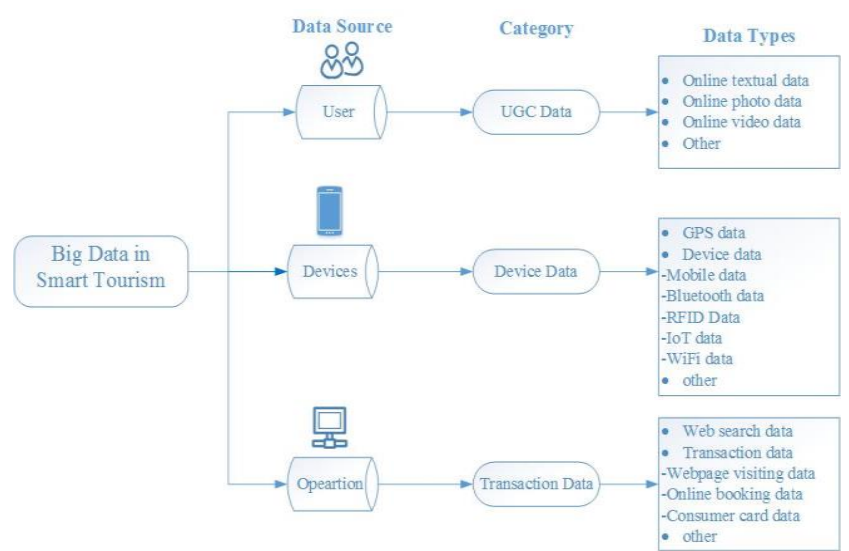

Fig. 1. Big data in tourism framework [18].

\section{A. Big Data in Tourism}

"Big data" has becoming a buzzword and very popular in the last decade. However, there does not exist an official definition of big data yet, different research has different definitions such as [18] "it refers to large data sets, large information sets requiring complex computational platforms in order to be analyzed" [19], "the proliferation of data, both structure and of computer processing power, data storage capacity, the use of computer to mediate transaction and social interactions, and the density of sensors, all at a decreasing cost" [20].

Even in early stage of big data in tourism, the rich data related to tourism was generated from three primary sources: users, devices and operation (in Fig. 1) [18], [20].

Frist, users generated data via social media which offered a capacious platform to spread User-Generation Content (UGC) in terms of online textual data, photos, videos, etc. [18], [21]. Second, big data in smart tourism was generated from sensor devices such as the Internet of Things (IoT), Global Position System (GPS) provides spatial-temporal location, mobile application data, Bluetooth data, etc. [18], [22]. Third, big data in smart tourism was generated from tourism operations (transaction activities or events in the tourism market) such as web searching, webpage visiting data, online booking and purchasing, etc. [18]. Based on the big data from these three main sources, tourist behavior and tourism market information has improved the effectiveness and efficiency of the tourism industry.

The prototype of smart tourism big data analysis is currently using the system architecture technology of Hadoop, Samza and Spark [17] that is summarized in Table I.

TABLE I: BIG DATA SYSTEM ARCHITECTURE [17]

\begin{tabular}{llll}
\hline \hline System & $\begin{array}{l}\text { Calculation } \\
\text { model }\end{array}$ & Describe & Developers \\
\hline Hadoop & $\begin{array}{l}\text { Batch } \\
\text { processing }\end{array}$ & $\begin{array}{l}\text { The first open source } \\
\text { implement of Map Reduce } \\
\text { paradigm }\end{array}$ & Apache \\
Spark & $\begin{array}{l}\text { Flow } \\
\text { calculation }\end{array}$ & $\begin{array}{l}\text { Apache distributed flow of } \\
\text { computing }\end{array}$ & TApache \\
Samza & $\begin{array}{l}\text { Batch } \\
\text { processing }\end{array}$ & $\begin{array}{l}\text { Support data memory and } \\
\text { the latest analysis system }\end{array}$ & $\begin{array}{l}\text { UC Berkeley } \\
\text { AMP Lab }\end{array}$ \\
\hline \hline
\end{tabular}

The big data system architecture shown in Fig. 1 consists of:

1) Hadoop: many companies using Hadoop to build their own distribution such as Facebook, Yahoo, Amazon and domestics Baidu, Alibaba and many Internet companies [17], [23]. Hadoop uses Map Reduce distributed computing framework according to GFS developed HDFS distributed file system [17].

2) Spark: supports the analysis system for memory data and recovery capabilities and is based on Hadoop with a number of architectural improvements. However, Hadoop uses hard disks to store data, and Spark uses memory to store data which can provide more than 100 times the speed of operation [24].

3) Samza: is a distributed stream processing framework in real time. Samza streams data processing, each Kafka cluster is connected to a cluster of Yarn and processes Samza jobs by processing real time steaming data such as log-service, real time services and data tracking applications [17], [25].

Hadoop, Spark and Samza are the most popular architecture design systems for big data analysis. Hadoop is suited for analysis off-line and complex big data processing; Spark is often used for off-line rapid big data processing and Samza is suited for analysis of large amounts of streaming data processing [17]. Thus, the study found that the structure 
of smart tourism data analysis system is more common in the areas of analysis.

\section{B. Mobile Application Support Tourism}

Mobile applications are consider as "software that provides information in various formats, according to the technical feature of the mobile devices for which they are designed and who can provide information and specific support to their users, being dedicated to daily and business activities" [14], [26]. Mobile applications in tourism have received scholar attention from both academic and practical perspectives [27]. The research of mobile application areas include approaches and methods to design and implement mobile travel systems and services [27], [28], user adoption studies [27]-[29], and business model formulation [30].

The mobile application implication on tourism provides potentially four types of functionality: navigation services, content-based services, social and communication services and commercial services [27]. The navigation services on mobile applications is routing a user from their current location to a preferred point of interest (POI) by displaying a map of the surrounding area [27], [31]. Content-based services refer to providing the traveler with personalization features that adapt the visualized content of the user, bookmarking which allows the user to add locations to an itinerary in order to better plan, manage, and share their leisure experience [32], [33]. Social and communication service supports connections between tourist and tourism business organizations such as accommodation, and other stakeholders involved in service provision and providing information of tourism experiences through websites and social media [34], [35]. Finally, commercial services support mobile purchases and reservations of tourism products and services [36]. The functional properties of mobile application guides follow the user experience of travel.

\section{System Design AND DeVElopment}

The research methodology using a System Development Life Cycle (SDLC) concept which includes the following:

\section{A. Big Data System Framework Design}

The big data system integrated with a mobile application was designed (see Fig. 2)

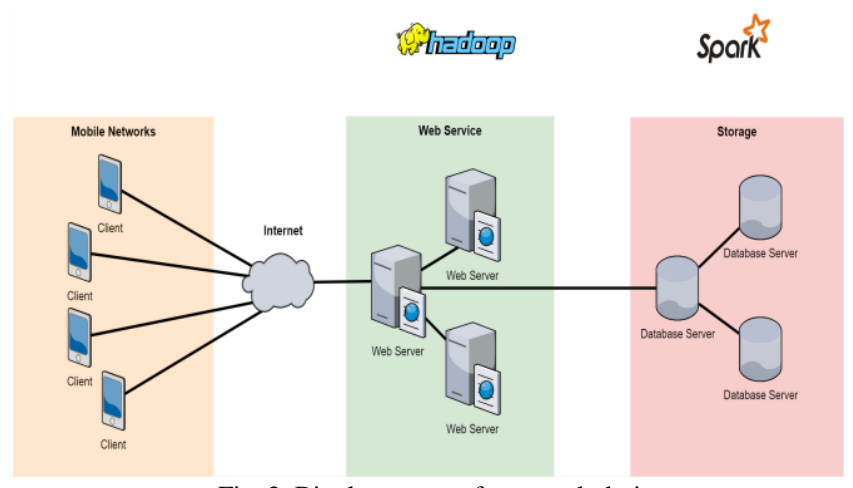

Fig. 2. Big data system framework design.

Fig. 2 shows the proposed approach which provides a model that integrates between a big data framework and a mobile application. In this section, the two main parts which are Big Data Frameworks and mobile applications will be discussed. Firstly, using Apache Hadoop as a big data processing framework. Apache Hadoop is an open-source software that was created to be a distributed processing framework for large data. One of the highlights of Hadoop is that it is designed to be used on computers that do not need high performance. Moreover, it is possible to expand the system or increase the number of devices easily in the future and it also has an automatic backup system, which makes it very popular for dealing with big data. Additionally, there is a tool for big data that is Apache Spark, it is a tool for making data processing created on Hadoop. It has the same functionality as Map Reduce, which features a processing speed, which is 10-100 times faster than Hadoop's MapReduce that allows to easily write a query.

In Apache Spark, there are libraries that are available for data processing, as follows:

1) Spark SQL is used to convert a dataset to a data frame format, allowing SQL commands to process data.

2) Spark Streaming is used for Real-Time processing.

3) MLlib is used for machine learning processing.

4) GraphX is used for Graph processing.

Apache Spark can run tasks on Hadoop, Standalone and On Cloud with various supported languages such as Scala, Java, Python, and R.

Apache Spark became popular and is applied in many businesses such as:

1) It provides stream processing, such as many video log files or social media feeds

2) It is used to analyze data by using machine learning (MLib).

3) It is interactive analytics for an interactive web.

4) It is used in Data Integration (via Spark SQL and Streaming).

Secondly, we propose an iOS mobile application which is an application developed for mobile devices, such as mobile phones and tablets. The program will help to meet the needs of users and support allowing users to use the phone more easily. Our application supports a very popular OS which is iOS.

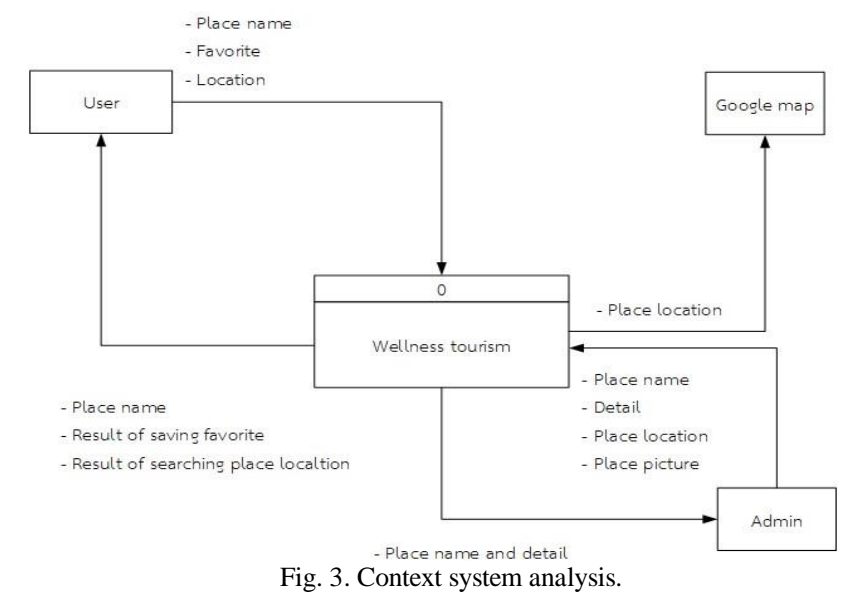

B. Mobile Application System on iOS Platform Analysis

The context diagram analysis of the mobile application 
system was shown in Fig. 3.

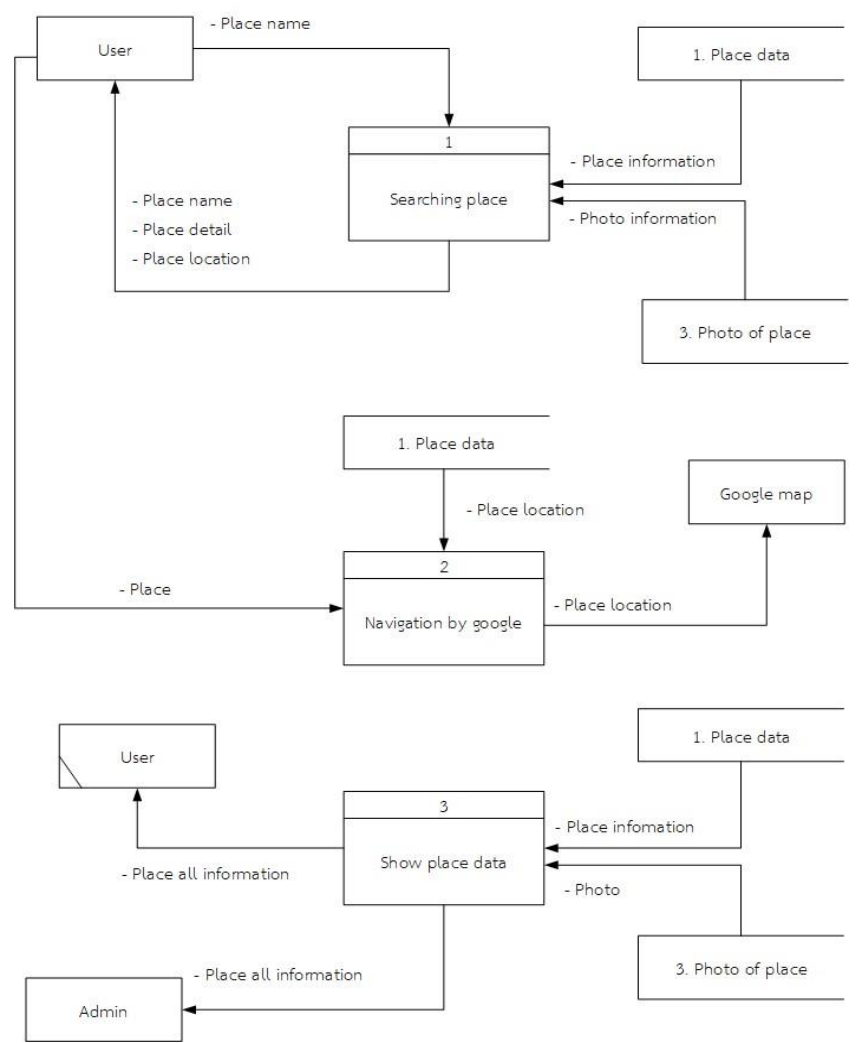

Fig. 4. Data flow diagram of the systems.

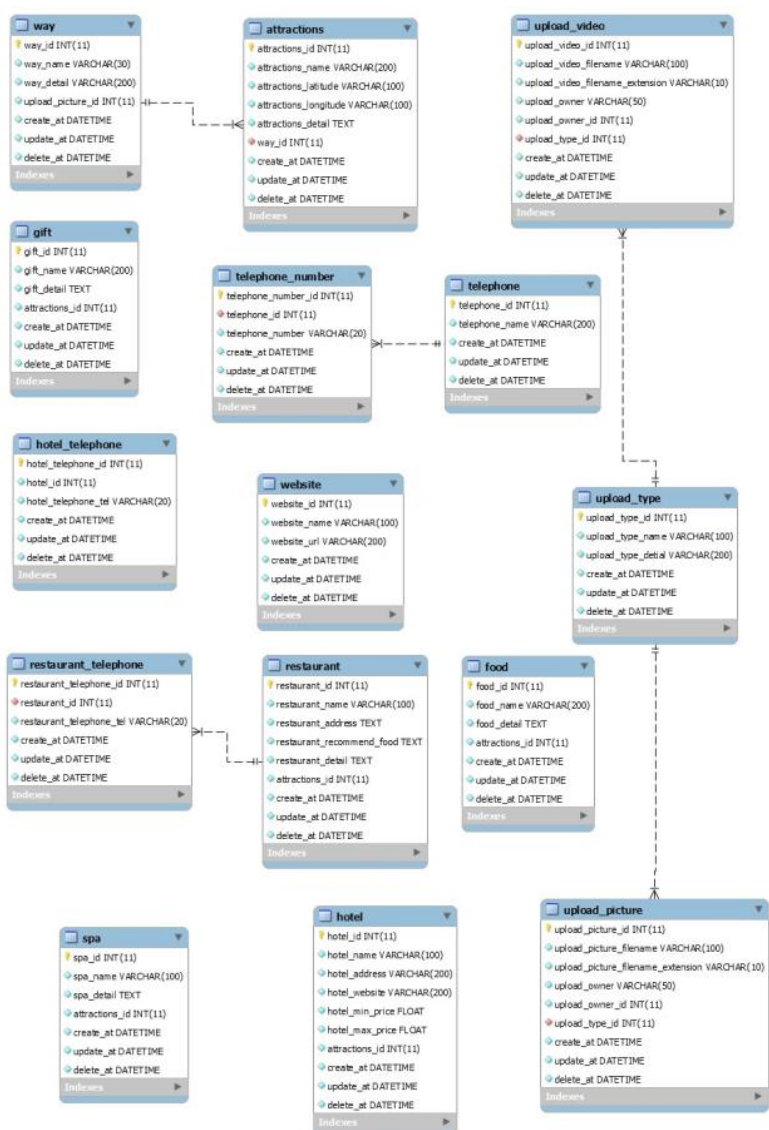

Fig. 5. Entity Relationship Diagram (ERD) of the systems.

Fig. 4 shows the DFD of the process of input data and output data flowing in our system. It shows how data is received from the initial phase and where it could be stored. The information stored in the database can then be viewed by the admin and users. Meanwhile the admin also has authority to manage all data by adding, editing/updating text, images and video. The information stored in the database cannot be changed by normal users.

The Entity Relationship Diagram (ERD) was designed as shown in Fig. 4. Some tables have relationships in each other, their relationships can be one-to-one or one-to-many, and many-many. For example, we set the attraction table's 'way' id as a foreigner key which is the 'way's' primary keyattraction. In this way, these two tables are related to each other, we can use the 'way' id to find all attractions. In our database, we create many foreigner keys in the tables to connect them to each other if the data is related.

\section{Mobile Application Design and Development}

The proposed system is an iOS mobile application that allows users to access different data from our data base. It consists of a mobile application and web server. The mobile application also can be installed on a mobile phone as a front-end of our system. It works with user interaction and can also receive various information from mobile devices.

The design of the iOS development describes the best practices involved with creating a successful application for the platform, placing particularly strong emphasis on captivating users by appealing to their storied connections with different places and incorporating interaction standards from the operating system itself (Fig. 6).

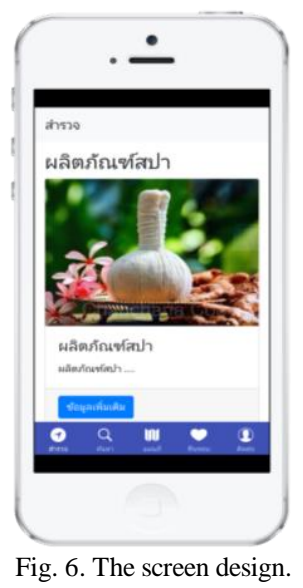

Beyond this simplicity and ease of use, applications should evolve with the iOS operating system, incorporating new user interface elements and presenting the correct type of information such as maps and other interface elements after users perform certain interaction requests (Fig. 7).

The application includes simple layouts, such as a grid table for displaying search results and an interactive interface for presenting details for a specific result. In addition, it includes an action bar with a list menu for selecting content screens, supporting users' knowledge of this user interface element from iOS.

Simple layouts lead to make each area of a screen's user interface easy to understand, allowing a particular screen in an application to seem user-friendly when viewed from a high-level perspective. The list of emergency telephone numbers which can be used easily when the tourist needs. It is very necessary for tourists in any cases (Fig. 8).

In designing the Navigator, the application is simplicity 
and accessibility. Indeed, iOS developers create applications which should remain as simple as possible so that users can still interact with the software while distracted or in an unfamiliar environment (Fig. 9).

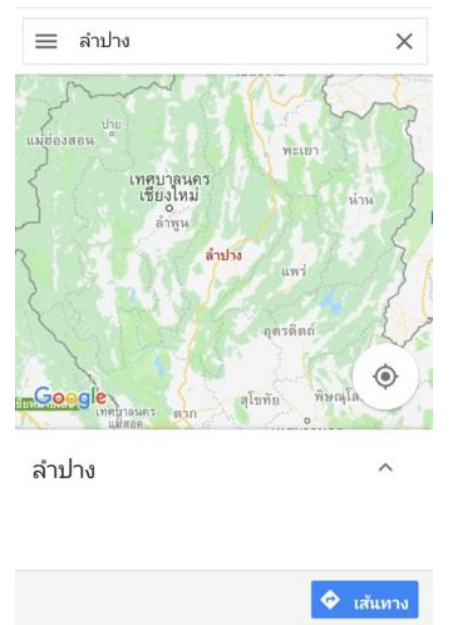

Fig. 7. The routing tourism.

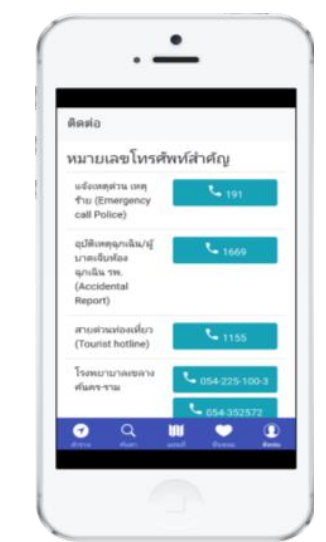

Fig. 8. Emergency phone call.

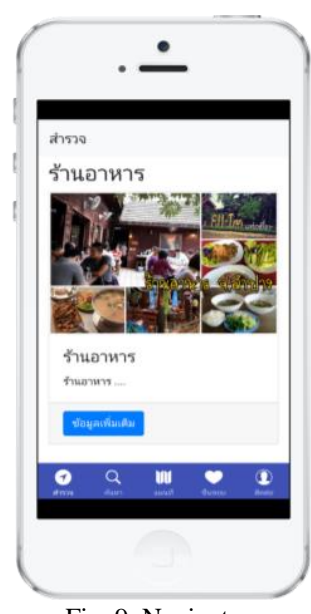

Fig. 9. Navigator.

While this application does not contain that many screens, there is some complexity in how users can navigate among them. Fig. 10 below shows the navigation hierarchy among the application's different screens. Users can access any other content screen by using the action bar, or they can return to the screen by selecting the "Search" button in the bottom-left corner of the screen. The path information screen presents a series of four paths, with place further details. This screen appears after users select the "Route" button next to a search result on the "Search Results" screen. The details that appear on this screen refer to the path. The photographs screen displays both detail and a gallery where users can view each of the images associated with a particular item, allowing them to appreciate the geographic and visual contexts of the location. Users can navigate to this screen from another content screen by selecting the name of that content screen, then by choosing the image. The images that appear on the screen can be chosen to view. In this example, users can view more information about food, spa's, and restaurants (Fig. 10).

\section{< เส้นทางการท่องเที่ยว}

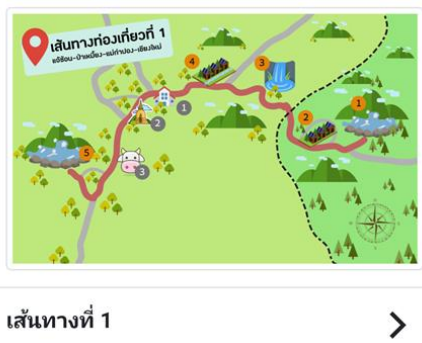

Fig. 10. Travel tourism routing.

After developing an integration of big data framework and a mobile application on iOS platform to support smart tourism at Lampang province in Thailand, it has been brought up on the Apple Store (Fig. 11), named "Wellness Tourism". The mobile application is becoming popular and has a very good rating score of 4.6 .

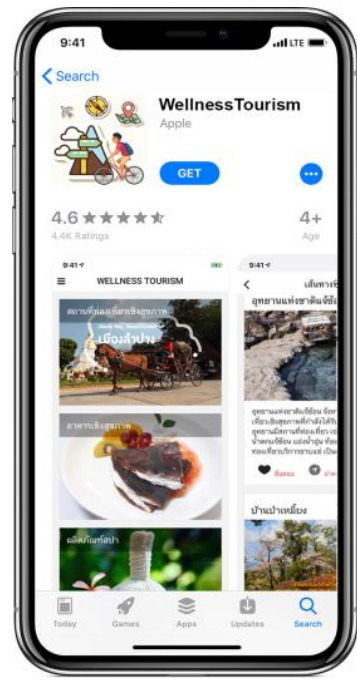

Fig. 11. Travel tourism routing.

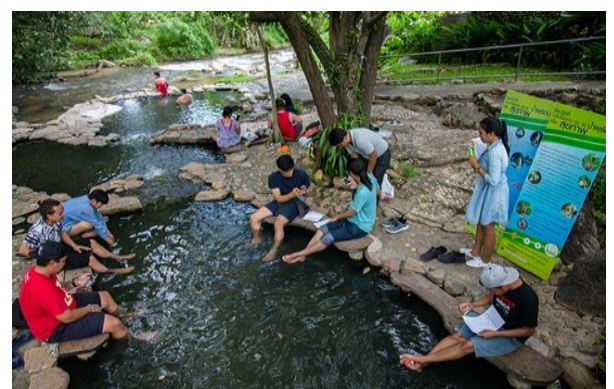

Fig. 12. Quantitative data was collected from questionnaire in the tourist attraction in Lampang Province, Thailand.

Finally, the mobile application has been used by users. We set up a seminar for transfer technology and training users 
especially government officers and stakeholders related to the Lampang Province tourism industry. The mobile application system has been evaluated by 400 users.

\section{System Evaluation}

\section{A. System Evaluation Method}

An integration of a big data framework and a mobile application on iOS platform to support a smart tourism system has been evaluated by users. This stage was conducted using a quantitative method. The population was 439,483 tourists in the research areas [37]. The sample size was 400 respondents based on Taro Yamane [38] with a confidence level of $95 \%(\alpha=0.05)$. The questionnaires were tried out and the Conbach Alpha coefficient was 0.935. The questionnaire comprised of 30 questions, of which 5 related to the demographic of the sample and the mobile application system evaluation with those using the Likert 5 scale ranging from $5=$ strongly agree, 4=agree, 3=moderate, $2=$ disagree, $1=$ strongly disagree. Data was analyzed using Microsoft Excel and SPSS software.

The qualitative data was collected from 10 users by an in-depth interview to evaluate the mobile application system performance and effectiveness. The qualitative data was analyzed by a content analysis method.

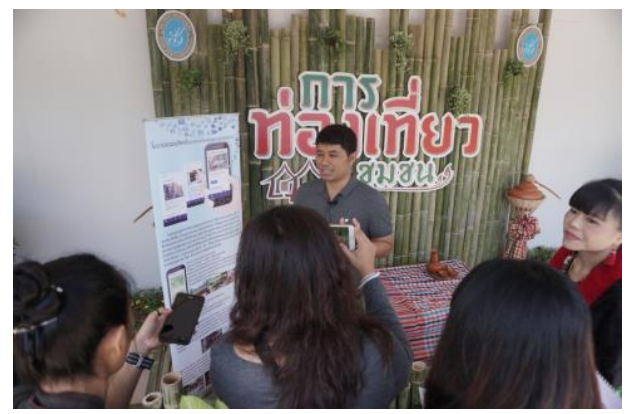

Fig. 13. Qualitative data was collected from in-depth interview user.

TABLE II: DEMOGRAPHIC OF THE RESPONDENT

\begin{tabular}{|c|c|c|}
\hline Variable & Frequency & Percent \\
\hline \multicolumn{3}{|l|}{ Gender } \\
\hline Male & 125 & 31.25 \\
\hline Female & 275 & 68.75 \\
\hline \multicolumn{3}{|l|}{ Age } \\
\hline$>20$ year & 160 & 40.00 \\
\hline 20-35 year & 130 & 32.50 \\
\hline $36-60$ year & 90 & 22.50 \\
\hline$<60$ years & 20 & 5.00 \\
\hline \multicolumn{3}{|l|}{ Education level } \\
\hline Under graduate & 175 & 43.75 \\
\hline Bachelor's degree & 80 & 20.00 \\
\hline Master's degree & 115 & 28.75 \\
\hline Ph.D. & 30 & 7.50 \\
\hline \multicolumn{3}{|l|}{ Occupation } \\
\hline Student & 225 & 56.25 \\
\hline Government officer & 75 & 18.75 \\
\hline Business owner & 20 & 5.00 \\
\hline Agriculture & 0 & 0.00 \\
\hline Private sector employee & 75 & 18.75 \\
\hline Other & 5 & 1.25 \\
\hline \multicolumn{3}{|l|}{ Income/month } \\
\hline$>10,000$ bath & 145 & 36.25 \\
\hline $10,001-20,000$ bath & 85 & 21.25 \\
\hline $20,001-30,000$ bath & 100 & 25.00 \\
\hline $30,001-40,000$ bath & 20 & 5.00 \\
\hline $40,001-50,000$ bath & 25 & 6.25 \\
\hline$<50,000$ bath & 25 & 6.25 \\
\hline
\end{tabular}

\section{B. Demographic of the Respondent}

The result of the system evaluation show in Table II and Table III.

The demographics of the respondents, found that most of them were female (68\%), aged less than 20 years (40\%), with an educational level of an undergraduate $(43 \%)$, occupation of a student $(56.25 \%)$ and an income of less than 10,000 Baht a month respectively.

\section{The Mobile Application System Evaluation}

The results of the mobile application system evaluation in six categories are shown in Table III.

TABLE III: THE MOBILE APPLICATION SYSTEM EVALUATION

\begin{tabular}{|c|c|c|}
\hline Variable & $\bar{x}$ & S.D. \\
\hline 1. Benefit of the mobile application system & 4.46 & 0.67 \\
\hline $\begin{array}{l}\text { 1.1 The mobile application system is important } \\
\text { for tourist to search information to support } \\
\text { their travel planning. }\end{array}$ & 4.44 & 0.65 \\
\hline $\begin{array}{l}\text { 1.2 The mobile application system is convenient } \\
\text { to provide information to tourists. }\end{array}$ & 4.50 & 0.65 \\
\hline $\begin{array}{l}\text { 1.3 The mobile application system is a tool that } \\
\text { assistances promote tourism. }\end{array}$ & 4.43 & 0.72 \\
\hline 2. Mobile application system design & 4.43 & 0.66 \\
\hline $\begin{array}{l}2.1 \text { The colors used in the application are } \\
\text { beautiful and feel comfortable. }\end{array}$ & 4.35 & 0.64 \\
\hline $\begin{array}{l}\text { 2.2 The size of the font in the application is clear, } \\
\text { easy to read. }\end{array}$ & 4.31 & 0.64 \\
\hline $\begin{array}{l}2.3 \text { The buttons in the application are properly } \\
\text { placed, easy to use. }\end{array}$ & 4.20 & 0.72 \\
\hline $\begin{array}{l}2.4 \text { Images used in the application are clear and } \\
\text { beautiful. }\end{array}$ & 4.50 & 0.63 \\
\hline $\begin{array}{l}\text { 3. Content providing by the mobile application } \\
\text { system }\end{array}$ & 4.32 & 0.65 \\
\hline $\begin{array}{l}\text { 3.1 The content in the mobile application system } \\
\text { clear, easy to understand. }\end{array}$ & 4.25 & 0.68 \\
\hline $\begin{array}{l}\text { 3.2 The content in the application has the } \\
\text { appropriate amount of data. }\end{array}$ & 4.29 & 0.68 \\
\hline $\begin{array}{l}\text { 3.3 Local wisdom food information is useful to } \\
\text { users }\end{array}$ & 4.33 & 0.65 \\
\hline $\begin{array}{l}\text { 3.4 Tourist attraction information is useful to } \\
\text { users. }\end{array}$ & 4.43 & 0.63 \\
\hline $\begin{array}{l}3.5 \text { Emergency call information is useful to } \\
\text { users. }\end{array}$ & 4.39 & 0.64 \\
\hline 3.6 Content meets the needs of users. & 4.20 & 0.68 \\
\hline 3.7 The content and images are consistent. & 4.38 & 0.60 \\
\hline $\begin{array}{l}\text { 3.8 Divide the topics in the mobile application } \\
\text { system into corresponding categories and can } \\
\text { be understood as needed. }\end{array}$ & 4.29 & 0.64 \\
\hline 4. The mobile application system easy to use & 4.32 & 0.68 \\
\hline $\begin{array}{l}\text { 4.1 The mobile application system is easy to use, } \\
\text { not complicated. }\end{array}$ & 4.48 & 0.63 \\
\hline 4.2 The mobile application is quick to process. & 4.15 & 0.71 \\
\hline $\begin{array}{l}\text { 4.3 The links within the mobile application } \\
\text { system are accurate. }\end{array}$ & 4.26 & 0.72 \\
\hline 4.4 Route navigation function is useful for users. & 4.39 & 0.66 \\
\hline $\begin{array}{l}\text { 5. The functionality of the mobile application } \\
\text { system. }\end{array}$ & 4.22 & 0.85 \\
\hline $\begin{array}{l}\text { 5.1 The mobile application system can be } \\
\text { installed and used easily. }\end{array}$ & 4.29 & 0.93 \\
\hline 5.2 The mobile application system is stable. & 4.15 & 0.76 \\
\hline $\begin{array}{l}\text { 6. Overall mobile application system satisfaction } \\
\text { and system effectiveness }\end{array}$ & 4.34 & 0.69 \\
\hline $\begin{array}{l}\text { 6.1 Overall mobile application system should be } \\
\text { recommended }\end{array}$ & 4.25 & 0.70 \\
\hline $\begin{array}{l}6.2 \text { Overall mobile application system is useful } \\
\text { and benefit to user }\end{array}$ & 4.33 & 0.74 \\
\hline $\begin{array}{l}\text { 6.3 Overall mobile application system is } \\
\text { effectiveness }\end{array}$ & 4.39 & 0.72 \\
\hline 6.4 Overall satisfaction & 4.38 & 0.60 \\
\hline
\end{tabular}

The result of the system evaluation of an integration of big a data framework and mobile application on an iOS 
platform to support smart tourism in case study at Lampang province in Thailand found six categories as follows.

1) The benefit of the mobile application system is a high-level score $(\bar{x}=4.46$, S.D. $=0.67)$. The highest level in this category found that the mobile application system is convenient to provide information to tourists $(\bar{x}=4.50$, S.D. $=0.65)$, second the mobile application system is important for tourist to search information to support their travel planning $(\bar{x}=4.44$, S.D. $=0.65)$, and third the mobile application system is a tool that assistances tourism promotion $(\bar{x}=4.43$, S.D. $=0.72)$, respectively.

2) The mobile application system design is a high-level score $(\bar{x}=4.43$, S.D. $=0.66)$. The highest level in this categories found that images used in the application are clear and beautiful $(\bar{x}=4.50$, S.D. $=0.63)$, second, the colors used in the application are beautiful and feel comfortable $(\bar{x}=4.35$, S.D. $=0.64)$, third, the size of the font in the application is clear, easy to read $(\bar{x}=4.31$, S.D. $=0.64)$, respectively.

3) The mobile application content design is a high-level score $(\bar{x}=4.32$, S.D. $=0.65)$. The highest level in this category found that the tourist attraction information is useful to users $(\bar{x}=4.43$, S.D. $=0.63)$, second, emergency call information is useful to users $(\bar{x}=4.39$, S.D. $=0.65)$, third, the content and images are consistent $(\bar{x}=4.38$, S.D. $=0.60$ ), respectively.

4) The mobile application system easy to use is a high-level score $(\bar{x}=4.32$, S.D. $=0.68)$. The highest level in this category found that the mobile application system is easy to use, not complicated ( $\bar{x}=4.48$, S.D. $=0.63)$, second, the route navigation function is useful for users $(\bar{x}=4.39$, S.D. $=0.66)$, third, the links within the mobile application system are accurate $(\bar{x}=4.26$, S.D. $=0.72)$, respectively.

5) The mobile application system functionality is a high-level score $(\bar{x}=4.22$, S.D. $=0.85)$. The highest level in this categories found that the mobile application system can be installed and used easily $(\bar{x}=4.29$, S.D. $=0.93)$ and the mobile application system is stable $(\overline{\mathrm{x}}$ $=4.15$, S.D. $=0.76$ ), respectively

6) Overall mobile application system satisfaction and system effectiveness is a high-level score $(\bar{x}=4.34$, S.D. $=0.69$ ). The highest level in this category found that the overall mobile application system is effective $(\bar{x}=4.39$, S.D. $=0.72)$, second, is overall satisfaction $(\bar{x}=4.38$, S.D. $=0.60)$, third, overall the mobile application system is useful and of benefit to the user $(\bar{x}=4.33$, S.D. $=0.74)$, respectively.

The overall mobile application system evaluation in six categories found the highest score is the benefit of the mobile application system $(\bar{x}=4.46$, S.D. $=0.67)$, second, the mobile application system design $(\bar{x}=4.43$, S.D. $=0.66)$, third, the mobile application content design $(\bar{x}=4.32$, S.D. $=0.65)$ and finally 4$)$ the mobile application system is easy to use $(\bar{x}$ $=4.32$, S.D. $=0.68$ ), respectively.

\section{Qualitative Result from the In-Depth Interview}

There were four main questions about the performance and system effectiveness, the results found that:
First, the user gets benefit from the mobile application system helping them to search reliability and trust the content and information about tourism attractions, accommodation, hotels, restaurants, spa's, and souvenir shops and was convenient to use.

"Normally we find information from Google and Pantip.com, sometimes we get the wrong information for example a review of a hotel in Lampang province which we decide to book, but when we arrival at the hotel, we are very disappointed because the hotel is not the same as in the review",

"This mobile application helped us to find reliable information and trust, therefore it can create a good experience of travel for use".

Second, the user is satisfied with the mobile application systems design because it easy to use with beautiful graphic design.

"I really like the 'tourism routing' because I cannot find it in Google Maps. Some of areas are very interesting to travel to, such as route no 4 , that promotes rock climbing activities. This is very new and very useful information. I can travel following the tourism route easily.

"I like the cartoon design of the map in the tourism route, I think is very cute"

"This system is suited for the elderly who are not familiar to use a smartphone, so they can use it easily"

The third user is satisfied with the functionality of the mobile application system, such as the emergency call that can alert the police and hospital in case of accident to support the safety tourism.

"I like the emergency call because I'm old and like to go to Jea-Son hot spring sometimes, it can be dangerous so this system can help me"

Finally, the overall satisfaction of users found that users have a high level of satisfaction for this mobile application and will recommend this application to others.

"This application is very useful and helpful especially senior tourist that travel alone because it was design to support tourism safety which I cannot find in any other applications"

"I will recommend this to my friends to download and use to assist their travel to Lampang province"

\section{Concussion And Future Perspective}

Big data and smart tourism is revolutionizing the way of the travel industry. The research study of using big data in smart tourism is still developing [4], [10], [18]. The benefit of using big data integrated with the smart tourism context can generate 'value experience' for the customer and improve the tourism business performance [4], [9], [10], [18], [26]. Therefore, this research studied the design of a prototype that integrates a big data framework and a mobile application on am iOS platform to support smart tourism in Lampang province, Thailand. The results found that the design of big data model using Apache Hadoop to co-ordinate with Apache Spark as the big data processing framework. The smart tourism system designed by using a 
mobile application as the user interface, data processing by using Hadoop on a web server and processing data in the database by using Spark. The development of the system focused on a mobile application system because it is very important feature of the smart tourism system. The mobile application was analyzed from the user's requirements including context diagrams, DFD and ER diagrams. The screen design is covered on the main menu, information about tourist attractions, accommodation, spa products, health food, wellness tourism routes, and emergency contact, etc. The system was developed on an iOS platform and uploaded to the Apple Store, which becoming popular with rating of score of 4.6. Finally, the user evaluated the effectiveness and satisfaction by 400 questionnaires and an in-depth interview with 10 people. The results of the quantitative data found that the overall mobile application system evaluation in six categories found the highest score of the mobile application system $(\bar{x}=4.46$, S.D. $=0.67)$, second the mobile application system design $(\bar{x}=4.43$, S.D. $=0.66)$, third the mobile application content design $(\bar{x}=4.32$, S.D. $=0.65)$ and finally fourth the mobile application system is easy to use ( $\bar{x}=4.32$, S.D. $=0.68)$, respectively. Furthermore, results from the qualitative data found that the user gets benefit from the mobile application system by helping them to search reliability and trust the content and information about tourism. Users were satisfied with the mobile application system design and the functionality of the mobile application system. Finally, overall the users have a high level of satisfaction of this mobile application system and will recommend this system to others.

Although, this research paper has accomplished its objective, there are additional studies and empirical research which may be taken in the future for the following issues:

1) The mobile application is develop as a prototype to test the an integration of a big data framework and a mobile application on an iOS platform can support smart tourism, therefore the research should develop the full scale of the smart tourism supply chain that should include support for tourism business transactions such as payments, hotel bookings and support online marketing.

2) Develop the mobile application on an Android platform because the number of users using Android is exponential growing and becoming important to the tourism industry.

3) Expand the areas that system covers to other important tourism cities of Thailand such as Bangkok, Phuket, Chiang Mai, Pattaya and Hua-Hin etc.

4) Develop the mobile application to support many languages such as Chinese, Japanese, Russian, German, etc.

\section{CONFLICT OF INTEREST}

The authors declare that there is no conflict of interests regarding the publication of this paper.

\section{AUTHOR CONTRIBUTIONS}

Suanpang presented idea of the paper and develop the big data framework and system analysis, design, implement and evaluation. Jamjuntr develop the mobile application and system testing. Suanpang and Jamjuntr contributed to the results. Suanpang took the lead in writing the manuscript. All the authors provided critical feedback and approved the manuscript.

\section{ACKNOWLEDGMENTS}

The authors are deeply grateful to Suan Dusit University and Siam Technology College for providing the Big Data Lab, which was used for testing the prototype and developing the mobile application.

\section{REFERENCES}

[1] J. Vaid and S. Kesharwani, "Role of big data analytics in social media marketing of MICE tourism," Global Journal of Enterprise Information System, vol. 10, pp. 55-61, January-March 2018.

[2] D. Buhalis, "The impact of ICT on tourism competition," Corporate rivalry and Market Power: Competion Issue in the Tourism Industry, pp. 143-177, London: IB Tauris, 2006.

[3] S. J. Miah, H. Q. Vu, J. Gammack, and M. McGrath, "A big data analytics method for tourist behavior analysis," Information \& Management, vol. 54, pp. 771-785, 2017.

[4] M. Fuchs, W. Hopken, and M. Lexhagen, "Big data analytics for knowledge generation in tourism destinations-A case from Sweden," International of Destination Marketing \& Management, vol. 3, pp. 198-209, 2014.

[5] J. Gantz and D. Reinsel, Extracting Value from Chaos, IDC iView, pp. $1-12,2011$.

[6] O. R. Team, Big Data Now: Current Perspective from O'Reilly Rader Sebastopol, USA: O’ Rielly Media, CA, 2011

[7] D. Laney, 3D Data Management Controlling Data Volume, Velocity and Variety, META Group research Note, 2011.

[8] A. Gandomi and M. Haider, "Beyond the hype: Big data concepts methods, and analytics," Int. J. Inf. Manage, vol. 35, pp. 137-144, 2015.

[9] P. D. Vecchio, G, M., V. Ndou, and G. Secundo, "Creating value from social big data: Implication for smart tourism destination," Information Processing and Management, vol. 54, pp. 847-860, 2018.

[10] D. Buhalis and A. Amaranggana, "Smart tourism destinations enhancing tourism experience through personalisation of services," Information and Communication Technologies in Tourism, Information and Communication Technologies in Tourism, Springer, Cham, pp. 377-389, 2015.

[11] Z. Xiang, Z. Schwartz, J. H. Gerdes, and M. Uysal, "What can big data and text analytics tell us about hotel guest experience and satisfaction?" Hosp. Manage, vol. 44, pp. 120-130, 2015.

[12] G. Phillips-Wren and A. Hoskisson, "An analytics journey towards big data,” Journal of Decision System, vol. 24, pp. 87-102, 2015.

[13] E. Marine-Roig and S. A. Clave, "Tourism analytics with massive users-generated content: A case study of Barcelona," Journal of Destination Market, vol. 4, pp. 162-174, 2015.

[14] K. Jieun, P. Yongtae, K. Chulhyun, and L. Hakyeon, Mobile Application Services Networks: Apple's App Store, Service Business, vol. 1, pp. 1-27, 2014.

[15] UNWTO. (2017). Tourism highlight 2017. [Online]. Available: https://www.e-unwto.org/doi/pdf/10.18111/9789284419029

[16] P. Suanpang, "The current using of social network of tourist and tourism business," Thailand Research Fund (TRF), Bangkok, Thailand, 2014.

[17] J. Chen, J. Tang, Q. Jiang, Y. Wang, and C. Tao, "Research on architecture of education big data analysis system," presented at the IEEE 2nd International of big data analysis, Beijing, China, 10-12 March, 2017.

[18] J. Li, L. Xu, L. Tang, S. Wang, and L. Li, "Big data in tourism research: A literature review," Tourism Management, vol. 68, pp. 301-323, 2018.

[19] J. Akoka, W. Comyn-Wattiau, and N. Laoufi, "Research on big data-A systematic mapping study," Computer Standard \& Interfaces, vol. 54, pp. 105-115, 2017.

[20] K. H. Price and R. Dunnigan, Big Data Analytics: A Practical Guide for Managers, FL: CRC Press Taylor \& Francise Group, 2015.

[21] Z. Xiang, Q. Du, Y. Ma, and W. Fan, “A comparative analysis f major online review platforms: Implications for social media analytics in hospitality and tourism," Tourism Management, vol. 58, pp. 301-323, 2017.

[22] N. Shoval, B. McKercher, E. Ng, and A. Birenboim, "Hotel location and tourist activity in cities," Annals of Tourism Research, vol. 38, no. 4, pp. 1594-1612, 2011. 
[23] C. Xuequi, J. Xiaolng, W. Yuanzhuo, G. Jiafeng, Z. T. Win, and L. Guojie, "Big data system and analysis technology," Journal of Software, vol. 9, pp. 49-59, 2016.

[24] F. Luiu, "Recommendation system based on big data analysis," Beijing: Beijing University of Posts and Telecommunications, p. 67, 2015.

[25] X. jingbo, W. Zekun, F. Kai, and C. Zhen, "Overview of research and application of Hadoop technology in cloud computer," Computer Science, vol. 9, pp. 6-11, 2016.

[26] T. M. Filofteia, "Mobile application for tourism study regarding their use by Romania," Annual of the Constantin Brancusi University of Targu Jiu, Economic Series, vol. 4, 2016.

[27] P. Kourouthanassisa, C. Boletsisb, C. Bardakia, and D. Chasanidou, "Tourists responses to mobile augmented reality travel guides: The role of emotions on adoption behavior," Pervasive and Mobile Computing, vol. 18, pp. 71-87, April 2015

[28] D. Gavalas and M. Kenteris, "A web-based pervasive recommendation system for mobile tourist guides," Pers. Ubiquitous Comput., vol. 15, no. 7, pp. 759-770, 2011.

[29] G. Ghiani, F. Paternò, C. Santoro, and L. D. Spano, "UbiCicero: A location-aware, multi-device museum guide interact," Comput., vol. 21 , no. 4, pp. 288-303, 2009

[30] S. Schmidt-Rauch and G. Schwabe, "Designing for mobile value co-creation - The case of travel counselling," Electron. Markets, pp. $1-13,2013$.

[31] Y. Suh, C. Shin, W. Woo, S. Dow, and B. MacIntyre, "Enhancing and evaluating users' social experience with a mobile phone guide applied to cultural heritage," Ubiquitous Comput., vol. 15, no. 60, pp. 649-665, 2011.

[32] D. Buján, D. Martín, O. Torices, D. López-de-Ipiña, C. Lamsfus, J. Abaitua, and A. Alzua-Sorzabal, "Context management platform for tourism applications," Sensors, vol. 13, pp. 8060-8078, 2013

[33] M. Bilandzic and M. Foth, "Urban computing and mobile devices: Mobile location bookmarking," IEEE Pervasive Comput, vol. 6, no. 3, pp. 53-57, 2007.

[34] D. Buhalis and L. Pistidda, "The impact of WiMAX on tourist destinations W," Information and Communication Technologies in Tourism, Springer, Vienna, pp. 383-394, 2008.

[35] C. Carlsson, P. Walden, and F. Yang, "Travel MoCo-A mobile community service for tourists," in Proc. 7th International Conference on Mobile Business, 7-8 July, 2008, pp. 49-58.

[36] J. M. Kwon, J. Bae, and S. C. Blum, "Mobile applications in the hospitality industry," J. Hosp. Tourism Technol, vol. 4, no. 1, pp. 81-92, 2013.
[37] Ministry of Tourism \& Sport. Domestic Tourism Statistics Q1-Q2 (Classify by region and province). [Online]. Available: https://www.mots.go.th/more_news.php?cid=531\&filename=index

[38] T. Yamane, An Introductory Analysis, 3rd ed. New York: Harper and Row Publication, 1976.

Copyright $\odot 2020$ by the authors. This is an open access article distributed under the Creative Commons Attribution License which permits unrestricted use, distribution, and reproduction in any medium, provided the original work is properly cited (CC BY 4.0).

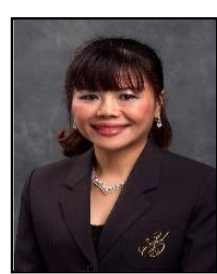

Pannee Suanpang was born in Thailand on January 29, 1976. She received her B.I.T bachelor of information systems and M.I.S. (master of information systems) from Griffith University, Australia in 1997 and 2001, respectively. She completed her DTech (doctor of technology in science) from University of Technology, Sydney, Australia, in 2005.

She is now working as an associate professor at the Department of Information Technology, Suan Dusi University. Her research interests lie in advanced information technology in agricultural, big data, IoT and smart tourism.

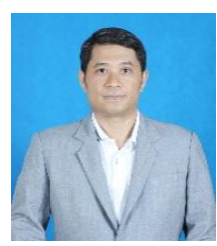

Pitchaya Jamjuntr was born in Thailand on December 6,1973 . He received his bachelor of engineering in electrical engineering from Suranaree University of Technology, Thailand, in 1998 and master of science in electronic commerce from National University, USA, in 2002, respectively.

$\mathrm{He}$ is currently pursuing a Ph.D in electrical and computer engineering from King Mongkut's University of Technology Thonburi, Thailand. He is now working as a lecturer at the Department of Computer Technology, Faculty of Engineering and Technology, Siam Technology College.

His research interests are in the areas of agriculture technology, image processing, big data, IoT, and artificial intelligence. 